\title{
Evaluation of Interleukin $1 \square$ Levels in Gingival Crevicular Fluid and Serum of Patients with Gingivitis and Chronic Periodontitis
}

\author{
Afnan Abdulkareem Hussain BDS, Basima Ghafory Ali BDS ,MSc \\ Periodontist/ Department of Periodontics /College of Dentistry/University of Baghdad
}

\begin{abstract}
:
Background: Interleukin-1 $(I L-1 \beta)$ is one of the most important cytokines which seems to have an important role in the inflammatory process in periodontal tissue and it has been correlated with periodontal diseases . The present study is aimed to evaluate the levels of interleukin-1 $\beta(I L-1 \beta)$ in gingival crevicular fluid and Serum of patients with gingivitis and chronic periodontitis and to explore whether the effect of IL-1 $\beta$ is due to its local production.
\end{abstract}

Subjects and method: Ninety males were enrolled in the present study. They were divided in to three main groups (50) patients have chronic periodontitis(CP), (25) gingivitis and (15) healthy control with an age ranging from (35-55) years. The Chronic periodontitis patients were subdivided into 2 subgroups according to their mean of pocket depth : subgroup I (PPD 4-6 mm) and subgroup II ( PPD $\geq 6 \mathrm{~mm}$ ). Plaque index, gingival index, bleeding on probing and probing pocket depth were recorded for all the subject. The gingival crevicular fluid was collected from each subject by using paper point (size 30) which was inserted into the gingival crevice and kept in place for 30 seconds. The fluid volume was determined by using a Periotron (Harco 6000 ). Serum samples were collected by using (Serum Separating Tubes).The concentration of interleukin $-1 \beta$ in gingival crevicular fluid and serum was quantified by a high-sensitivity enzyme linked immunosorbent assay.

Results :The mean concentration of crevicular interleukin $1 \beta \quad(\mathrm{pg} / \mu \mathrm{l})$ was higher in Chronic periodontitis group ( $275.61 \pm 60.63)$ than in gingivitis group $(174.04 \pm 57.09)$ and in control group $(72.96 \pm 27.82)$.In addition, the concentration of serum IL-1 $\beta$ ( pg/ $/ \mathrm{l})$ was found equal in chronic periodontitis group

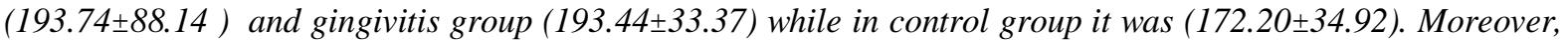
all the clinical parameters were higher in subgroup II than in subgroup I. The descriptive statistics for serum and crevicular IL-1 $\beta$ concentration ( $\mathrm{pg} / \mu \mathrm{l})$ was elevated in subgroup II in comparison with subgroup I.A high significant difference in the concentration of $I L-1 \beta$ in GCF compared to serum concentration in chronic periodontitis and control group P-value (0.000 and 0.001) respectively and between subgroups. while a significant difference found in Gingivitis group P-value (0.042).

Conclusion: The findings of the present study indicated that the concentration of crevicular IL-1 $\beta$ was higher in Chronic periodontitis group than in gingivitis group and in control group and can be consider as monitor marker which give information about periodontal disease progression. The IL-1 $\beta$ level in serum was very low in comparison to its level in gingival crevicular fluid, this difference may be due to that IL-1B is produce locally and acts on the local environment.

keywords: chronic periodontitis, interleukin-1 $\beta$, Gingival crevicular fluid

\section{Introduction}

Chronic periodontitis is the most prevalent type of periodontal disease (1). Although, periodontal bacteria are the main causative factors inducing the initiation of periodontitis subsequent progression and disease severity are also determined by the host immune response (2).

Following the initiation of the immune response, instigated by bacterial pathogens, a number of different inflammatory mediators or biomarkers are produced by various cellular elements. These proinflammatory mediators are commonly known as cytokines. When working together to modulate cellular functions they are known as cytokine networks and are part of the innate immune system (3). The host defense system, including innate and adaptive immunity, is responsible for combating the pathologic bacteria invading the periodontal tissue. Failure to eradicate the invading pathogens will result in a continuous state of inflammation where inflammatory cells such as lymphocytes, PMNs, and macrophages will continue to produce inflammatory mediators in an effort to destroy the invaders. Unfortunately, these inflammatory mediators have a deleterious effect on the host tissue as well as foreign microbes. One of the effects of these mediators on the host is the induction of matrix degradation and bone resorption through activation of proteases and other inflammatory mediators that activate osteoclasts(4).It has been postulated that cytokines are central to the pathogenesis of number of diseases, including periodontal disease (5). Cytokines are small proteins secreted 
from many cell types that regulate the nature, intensity, and duration of the immune response (6). For example, IL1 $\beta$, IL6, and tumor necrosis factor (TNF) $\alpha$ are considered pro inflammatory mediators. Conversely, IL1 receptor antagonist, IL4, IL10, IL11, and IL13 can suppress the production of inflammatory cytokines (7).

Interleukin (IL)- 1 is found in two active forms, IL- $1 \alpha$ and IL-1 $1 \beta$ encoded by separate genes. Both are potent proinflammatory molecules and are the main constituents of what was once called osteoclast-activating factor (8). IL1 is produced by Macrophages and marrow stromal cells .It stimulates bone resorption and implicated in pathological conditions with bone loss (9). IL-1 $\beta$ has been found to be significantly increased in the periodontal tissues and GCF from diseased sites, compared with healthy sites (10). (Bloemen et al.,2011) $)^{(11)}$ showed that just a single exposure of IL-1 $\beta$ can shift the phenotype of osteoblast-like cells from one that favors bone formation to one that supports bone destruction.

Early diagnosis of periodontal diseases will surely help in reducing the morbidity rate of the teeth. Periodontal disease risk can be identified and quantified by objective measures, like biomarkers (12). It has been a feature of periodontal diseases that it creates an area of local inflammation as well as systemic inflammation, which are indicated by elevated serum levels of various pro-inflammatory markers .Inflammatory mediators were assessed in various material collected from patients with periodontal disease which this better analysed by estimating the levels of some inflammatory mediators in gingival crevicular fluid or gingival tissue (13).

Gingival crevicular fluid (GCF) is an inflammatory exudate which can be collected in the gingival sulcus. The function of GCF is to flush debris from the gingival crevice. When this fluid passes through the gingival tissues, it accumulates host derived enzymes, inflammatory mediators and tissue breakdown products which can be analyzed and examined by collecting it in the gingival crevice (14). (Bergmann \& Deinzer 2008) (15) $^{(15)}$ demonstrated that both the concentration and total amount of IL-1 $\beta$ in GCF varies throughout the day. The present study was conducted to compare the levels of IL-1 $\beta$ in GCF and serum and to evaluate and correlate the concentration of IL- $1 \beta$ in GCF and serum with different probing depths and to verify if the effect of IL- $1 \beta$ is due to its local production.

\section{Subjects}

\section{Materials And Methods}

Ninety males were enrolled in the present study with an age ranging from (35-55) years. All were from attendants to department of periodontics, college of Dentistry University of Baghdad. All subjects were in good general health and had not received previous periodontal therapy or taken antibiotics ,immunomodulatory or anti-inflammatory drugs in the 3 months before the study. Smokers, patients requiring antibiotic prophylaxis for dental treatment, patients with any systemic disease, or those who were on long-term medication that could affect the expression of gingivitis or periodontitis were excluded from the study. A written explanation of the purpose of the study was provided for each subject and signed consent according to the Helsinki Declaration was obtained. Institutional ethics review committee approval for the study was obtained. Full periodontal examinations were carried out on each patient and the participants were then divided into three main groups (50) patients have chronic periodontitis, (25) gingivitis, and (15) healthy control. The chronic periodontitis patients were subdivided according to the mean of their pocket depth to two subgroups: subgroup I ( 26) patients with pocket depth (4-6mm) and subgroup II (24) patients with pocket depth equal or more than $6 \mathrm{~mm}$.

\section{Gingival Crevicular Fluid sampling}

To avoid contamination with saliva, only teeth of the upper jaw were selected. Immediately following isolation and removal of supragingival plaque, paper point (size 30) were inserted into the gingival crevice until mild resistance was felt, and kept in place for 30 seconds. The fluid volume was determined by using a Periotron (Harco, 6000 ), contaminated paper point with blood were excluded. Following collection of GCF the paper point placed in eppendroffs tubes contain (300 micro liter) phosphate buffer saline. GCF was eluted from paper point by centrifugation at $3000 \mathrm{rpm}$ for 15 minutes after that the paper point was removed and GCF sample kept at $-40{ }^{\circ} \mathrm{C}$ till analysis.

\section{Collection of Blood samples}

At the time of the appointment 5-ml of venous blood were collected from each patient and control. The blood samples were centrifuged for 15 minutes at $1000 \mathrm{rpm}$ the separation serum sample kept at $-40{ }^{\circ} \mathrm{C}$ till used.

\section{periodontal assessment}

The periodontal examinations were performed on dental chair; they were recorded on four sites (mesial, distal, buccal and lingual) for all teeth except the third molar, The periodontal parameters included Plaque index (PLI) (16), Gingival index (GI) (17), Bleeding on probing (BOP) (18) and Probing pocket depth (19). 


\section{Detection of IL-1 $\square$}

The presence of cytokine in the gingival crevicular fluid and serum samples was determined by using commercial enzyme linked immune sorbent assay kits. The kits detected human IL-1 $\beta$. (Serum IL1- $\beta$, CUSABIO kit, China) and (Salivary IL1- $\beta$ kit, SALIMETRICS ,USA.). Concentrations of the cytokine in GCF and serum me as ured in ( $\mathrm{pg} / \mu \mathrm{l}$.) .

\section{Statistical Analyses}

The data were processed and analyzed using (SPSS. Inc, version 17) descriptive statistics include(mean, standard deviation and median) inferential statistics(Kruskal-Wallis $\mathrm{H}$ test, Mann-Whitney U test and Wilcoxon Signed Ranks test)

In the statistical evaluation, the following levels of significance were used:

\begin{tabular}{|l|l|}
\hline $\mathrm{P}>0.05$ & NS Non-significant \\
\hline $0.05 \geq \mathrm{P}>0.01$ & $\mathrm{~S} \quad$ Significant \\
\hline $\mathrm{P} \leq 0.01$ & HS Highly significant \\
\hline
\end{tabular}

\section{Results}

The descriptive statistical results of clinical parameters (PLI, GI and BOP) for each group were found to be higher in chronic periodontitis group than in gingivitis group and definitely than in control group. Also, all clinical parameters higher in subgroup II than subgroup1 as shown in tables (1) and (2).

Inter groups comparisons of crevicular IL-1 $\beta$ concentration $(\mathrm{pg} / \mu \mathrm{l})$ showed highly significant differences between all studied groups and subgroups p-value (0.000) as shown in tables (3) and (4).

While, Inter groups comparisons of serum IL-1 $\beta$ concentration (pg/ $\mu \mathrm{l})$ by using Kruskal-Wallis $\mathrm{H}$ test and Mann-Whitney $\mathrm{U}$ test showed non significant differences between all studied groups and subgroups as shown in tables (5) and (6).

The median concentration $(\mathrm{pg} / \mu \mathrm{I})$ of IL-1 $\beta$ was found to be elevated in GCF compared to serum concentration in chronic periodontitis and control groups with high significant difference P-value $(0.000$ and $0.001)$ respectively. while significant difference found in Gingivitis group P-value (0.042). This statistic result was obtained by using Wilcoxon Signed Ranks test Table (7).

Also, a high significant difference was observed between the crevicular and serum concentration of IL-1 $\beta$ with subgroup I p-value (0.001) and subgroup II p-value (0.002) as shown in Table ( 8).

Table 1:Descriptive statistics for Immunological and clinical Parameters for all studied groups

\begin{tabular}{|c|c|c|c|c|c|c|c|c|c|}
\hline \multirow[t]{2}{*}{ variable } & \multicolumn{3}{|c|}{$\begin{array}{l}\text { Chronic periodontitis } \\
\text { Group }\end{array}$} & \multicolumn{3}{|c|}{ Gingivitis group } & \multicolumn{3}{|c|}{ Control group } \\
\hline & Median & Mean & \pm S.D. & Median & Mean & \pm S.D. & Median & Mean & \pm S.D. \\
\hline PLI & 1.005 & 1.06 & 0.35 & 0.6 & 0.64 & 0.12 & 0.31 & 0.31 & 0.07 \\
\hline GI & 1.24 & 1.27 & 0.38 & 0.61 & 0.62 & 0.12 & 0.35 & 0.31 & 0.48 \\
\hline BOP & 40.09 & 41.95 & 26.19 & 15.63 & 21.96 & 15.61 & $\mathbf{0}$ & 1.29 & 1.77 \\
\hline PPD & 5.375 & 5.79 & 1.63 & ------ & ----- & --.-- & ------- & $\begin{array}{l}----- \\
\end{array}$ & ---- \\
\hline$\overline{\text { C IL-1 } \square}$ & 288.065 & 275.6 & 60.36 & 153.91 & 174.04 & 57.09 & 76 & 72.96 & 27.82 \\
\hline S IL-1 $\square$ & 184.5 & 193.7 & 88.14 & 195 & 193.44 & \begin{tabular}{|l|}
33.73 \\
\end{tabular} & 191 & 172.2 & 34.92 \\
\hline
\end{tabular}

Table 2: Descriptive statistics for Immunological and clinical Parameters for subgroup 1\&11

\begin{tabular}{|c|c|c|c|c|c|c|}
\hline \multirow[b]{2}{*}{ variable } & \multicolumn{3}{|c|}{ Subgroup I(4-6)mm } & \multicolumn{3}{|c|}{ Subgroup II( $\square$ 6)mm } \\
\hline & Median & Mean & \pm S.D. & Median & Mean & \pm S.D. \\
\hline PLI & 1.025 & 1.05 & 0.35 & 0.98 & 1.06 & 0.36 \\
\hline GI & 1.14 & 1.20 & 0.32 & 1.315 & 1.36 & 0.43 \\
\hline BOP & 26.5 & 28.69 & 14.96 & 51 & 48.25 & 22.45 \\
\hline PPD & 4.24 & 4.35 & 0.43 & 7.16 & 7.34 & 0.81 \\
\hline C IL-1 $\square$ & 249.54 & 238.91 & 59.25 & 309.55 & 315.36 & 27.85 \\
\hline S IL-1 $\square$ & 192.5 & 190.58 & 29.26 & 182.5 & 197.17 & 124.88 \\
\hline
\end{tabular}


Table 3 : Significant difference in crevicular IL-1 $\square$ concentration between all studied groups

\begin{tabular}{|l||l||l||l||l||}
\hline Groups & Median & Kruskal-Wallis H test & d.f. & p-value \\
\hline \hline Control & $\mathbf{7 6}$ & & & \\
\cline { 1 - 2 } Gingivitis & $\mathbf{1 5 3 . 9 1}$ & 52.775 & 2 & $\begin{array}{l}0.000 \\
\text { (HS) }\end{array}$ \\
\hline \hline C.P & $\mathbf{2 8 8 . 0 6 5}$ & & & \\
\hline
\end{tabular}

Table 4: Comparison between subgroup I and subgroup II in relation to crevicular IL-1B concentration

\begin{tabular}{|l|l||l||l|}
\hline Groups & Median & Mann-Whitney U test & p-value \\
\hline \hline subgroupI & $\mathbf{2 4 9 . 5 4}$ & \multirow{2}{*}{28} & $\begin{array}{l}0.000 \\
\text { (HS) }\end{array}$ \\
\hline \hline subgroupII & $\mathbf{3 0 9 . 5 5}$ & & \\
\hline
\end{tabular}

Table 5: Significant difference in serum IL-1 $\square$ concentration between studied groups

\begin{tabular}{|l||l||l|l|l||}
\hline Groups & Median & Kruskal-Wallis H test & d.f. & p-value \\
\hline \hline Control & 191 & & & \\
\cline { 1 - 2 } Gingivitis & 195 & 2.294 & 2 & $\begin{array}{l}0.318 \\
\text { (NS) }\end{array}$ \\
\hline \hline C.P & 184.5 & & & \\
\hline
\end{tabular}

Table 6: Significant difference of serum IL-1 $\square$ between subgroup I and subgroup II

\begin{tabular}{|l|l|l|l|}
\hline Groups & Median & Mann-Whitney U test & p-value \\
\hline Subgroup I & 192.5 & \multirow{2}{*}{265.5} & $\begin{array}{l}\text { 0.366 } \\
\text { (NS) }\end{array}$ \\
\hline SubgroupII & 182.5 & & \\
\hline
\end{tabular}

Table7: Significant difference between crevicular and serum concentration of IL-1 $\square$ in the studied groups

\begin{tabular}{|l|l||l|}
\hline Groups & Wilcoxon Signed Ranks test & p-value \\
\hline \hline C.P & -4.667 & $0.000(\mathrm{HS})$ \\
\hline \hline Gingivitis & -2.031 & $0.042(\mathrm{~S})$ \\
\hline \hline Control & -3.408 & $0.001(\mathrm{HS})$ \\
\hline
\end{tabular}

Table 8: Significant difference between crevicular and serum IL-1 $\square$ in the subgroups

\begin{tabular}{|l||l|l|}
\hline Subgroups & Wilcoxon Signed Ranks test & p-value \\
\hline \hline Subgroup I(4-6) & -3.213 & $0.001(\mathrm{HS})$ \\
\hline \hline subgroupII ( $\square$ 6) & -3.057 & $0.002(\mathrm{HS})$ \\
\hline
\end{tabular}

\section{Discussion}

The results of the present study have shown that there was a significant difference in the concentration of crevicular IL-1 $\beta$ in GCF between the chronic periodontitis, gingivitis and control groups as well as between the two subgroups according to their different probing depths. These findings were in agreement with results of many studies $(20,21)$ who showed that the concentration of IL-1 $\beta$ in GCF in patients with periodontitis was higher than in those with gingivitis and those with clinically healthy periodontium . Also the gingivitis group showed significantly higher levels of IL-1 $\beta$ than the control group. In addition, level of IL$1 \beta$ was significantly higher at active sites than at in active sites that's mean the amount of this cytokine in the GCF is associated with the stage of periodontal disease. In addition the present study is in consistent with the studies of $[22,23,24,25]$ that reported an increased IL-1 $\beta$ levels in GCF from diseased sites compared with healthy sites Moreover, ( 26) demonstrated higher total amounts of IL-1 $\beta$ in patients with severe periodontitis compared with those with mild periodontitis and healthy individuals. These results indicated that shifting in the balance between the activities of pro- inflammatory and anti-inflammatory cytokines during the periodontal inflammation could affect the intensity and duration of inflammation

On contrast to the present study, Rawlinson et al. ,2003 ${ }^{(23)}$ reported lower concentrations of IL-1 $\beta$ at diseased sites in comparison with healthy sites in both smokers and non-smokers. 
The range of IL-1 $\beta$ concentrations in GCF is often quite variable $(\mathbf{2 7 , 1 5})$. These variability in many studies may reflect the complex multifactorial nature of the disease and differences in sampling techniques and assays used for analysis.

In the present study there was a non significant difference in serum IL-1 $\beta$ concentration between all studied groups and subgroups. These findings are in consistent with some studies which mentioned that there were no differences in the concentrations of IL- $1 \beta$ between CP patients and healthy control $(28,29)$

In contrast to the present study (30) revealed that there was a significant elevation in median serum IL-1 $\beta$ level among CP patients in comparison to that of healthy control. Also, Gorska et al.,2003 ${ }^{(31)}$ in Poland, found that the concentrations of IL- $1 \beta$ were significantly higher in serum and gingival tissue biopsies in chronic periodontitis patients as compared to healthy control. In addition ,Zhraa $2011^{(32)}$ documented that the detection of elevated levels of serum IL-1 $\beta$ in the serum of subjects with $\mathrm{CP}$ was consistent with the cytotoxins role in inflammation and suggests that the serum IL-1 $\beta$ may be a good marker of periodontal inflammation .

The present study showed that there was a high significant difference in concentration of IL-1 $\beta(\mathrm{pg} / \mu \mathrm{I})$ in GCF compared to serum concentration with in all studied groups and subgroups. This result is in agreement with Orozco et al., 2006 ${ }^{(21)}$ who found very low levels of cytokines (IL-1 $\beta$, IL-12 and IL-18) in the serum when compared to crevicular level. Also, Gorska et al., $2003\left({ }^{31)}\right.$ reported that Serum cytokines do not accurately reflect the presence or severity of periodontitis. This may be due to host variability and confounding factors. Gorska do their study for (IL-1 $\beta$, TNF- $\alpha$, IL-2, IFN- $\square$, IL-4, IL-10) cytokines on gingival tissue biopsy and found that the level of cytokines were higher in gingival tissue biopsies when compared to serum level. This confirms that these mediators are produced locally in periodontitis site. But the serum level of cytokine although its less than the crevicular level, this may reflect the systemic effect of periodontitis to subject the patient for other systemic disease but this need further analysis for long period of time.

\section{References}

[1]. Armitage GC (). Development of a Classification System for Periodontal Diseases and Conditions. Ann. Periodontol1999. 4: $1-6$.

[2]. Kornman KS, Knobelman C, Wang HY. Is periodontitis genetic? The answer may be Yes! J Mass Dent Soc. 2000;49:26-30

[3]. Herbert I Bader.Clinical and Systemic Implications of Periodontal Disease Susceptibility: The Importance of IL-6 Polymorphism Bader, Dentistry 2014, 4:1.

[4]. Rayyan A Kayal. The Role of Osteoimmunology in Periodontal Disease. BioMed Research International .Volume 2013 (2013), ArticleID639368,12pages.

Gemmell E, Seymour GJ. Immunoregula- tory control of Th1/Th2 cytokine profiles in periodontal disease. Periodontol 2000. 2004;35: 21-4.

[5]. Commins SP, Borish L, Steinke JW. Immunologic messenger molecules: cytokines, interferons, and chemokines. J Allergy Clin Immunol 2010;125(2 Suppl 2):S53-72.

[6]. Zhang D, Goetz W, Braumann B, Bourauel C, Jaeger A. Effect of soluble receptors to interleukin-1 and tumor necrosis factor alpha on experimentally induced root resorption in rats. J Periodontal Res 2003;38(3):324-32.

[7]. Graves DT, Cochran D . The contribution of interleukin-1 and tumor necrosis factor to periodontal tissue destruction. J Periodontol.2003; 74:391-401.

[8]. Christopher G Rosenvall .Trauma and Cytokines: Gingival Crevicular Fluid Biomarkers in Traumatized Permanent Incisors. A master thesis. The Ohio State University.2013.

[9]. Stashenko P, Fujiyoshi P, Obernesser MS, ProstakL, Haffajee AD, Socransky SS. Levels of interleukin 1 beta in tissue from sites of active periodontal disease. J Clin Periodontol. 1991; 18:548-54. from tahran rabati article

[10]. Bloemen V, Schoenmaker T, de Vries TJ, Everts V. IL-1beta favors osteoclastogenesis via supporting human periodontal ligament fibroblasts. J Cell Biochem 2011;112(7):1890-7.

[11]. O'Connel PA. Effects of periodontal therapy on glycemic control and inflammatory markers. J Periodontol 2008;79:774-83.

[12]. Małgorzata Nędzi-Góra, Jolanta Kostrzewa-Janicka, Renata Górska Markers of inflammation in periodontal diseases.(Centr Eur J Immunol 2013; 38 (3): 363-366)

[13]. Javed F, Al- Hezaimi K, Salameh Z, Almas K, Romanos GE. Proinflammatory cytokines in the crevicular fluid of patients with periimplantitis.Cytokine .2011;53(1):8-12.

[14]. Bergmann A, Deinzer R.Daytime variations of interleukin-1beta in gingival crevicular fluid.Eur J Oral Sci. 2008;1 16(1):18-22.

[15]. Silness P and Löe H. Periodontal disease in pregnancy. Acta Odontol Scand. 1964; 22: 121.

[16]. Löe H. The gingival index, the plaque index and the retention index system.J Periodontal. 1967; 38(6): 610-616.

[17]. Carranza FA: Carranza's Clinical Periodontology, 10th edition, Missouri,Saunders Company, 2009.

[18]. Lang NP, Bartold PM ,Cullinam M, et al. International classification workshop. Consensus report: chronic periodontitis . Annals of Periodontology, 1999;4:53.

[19]. perozini,Leao,Qewiroz. GCf biochemical markers in periodontal disease.Quintessence International .2010;41(10).

[20]. Orozco A, Gemmell E, Bickel M, Seymour GJ. Interleukin-1b, interleukin-12 and inter- leukin-18 levels in gingival fluid and serum of patients with gingivitis and periodontitis.Oral Microbiol Immunol. 2006;21: 256-260.

[21]. Gonza 'es JR, Herrmann JM, Boedeker R H, Francz P. I., Biesalski H. \& Meyle J. Concentration of interleukin-1beta and neutrophil elastase activity in gingival crevicular fluid during experimental gingivitis. Journal of Clinical Periodontology.2001; 28:544-549.

[22]. Rawlinson A, Grummitt JM , Walsh TF and Ian DCW. Interleukin 1 and receptor antagonist levels in gingival crevicular fluid in heavy smokers versus non-smokers. J Clin Periodontology. 2003;30(1):42-8.

[23]. Chaudhari AU , Byakod GN , waghmare PF, Krarhadkar VM .correlation level of IL-1 $\beta$ in gingival crevicular fluid to the clinical parameters of chronic periodentitis. Journal of contemporary Dental practice, 2011;12(1):52-59

[24]. Lukasz Gilowski. Amount of interleukin-1 $\beta$ and interleukin-1 receptor antagonist in periodontitis and healthy patients. Archives of Oral Biology. 2014; 59( 7):729-734. 
[25]. Engebretson SP, Grbic JT, Singer R \&Lamster IB. GCF IL-1beta profiles in periodontal disease. Journal of Clinical

[26]. Lee HJ, Kang IK, Chung CP\& Choi SM .The subgingival microflora and gingival crevicular fluid cytokines in refractory periodontitis. Journal of Clinical Perio- dontology .1995;(22) 885-890.

[27]. Yucel OO, Berker E, Gariboğlu S, Otlu H. Interleukin-11, interleukin-1beta, interleukin-12 and the pathogenesis of inflammatory periodontal diseases. J Clin Periodontol. 2008;35(5):365-70.(www.ivsl.org)

[28]. Queiroz AC, Mario T , O'Connell PA,Nóbrega PB,Costa PP.Inflammation markers in healthy and periodontitis patients. Apreliminary data screening. Braz. Dent. J. 2008;19(1).

[29]. Batool H Al-Ghurabei1, Zahraa F. Shaker, Raghed Fadhel, Nahla G Al-Khayli, Leen K Mustafa.Serum Levels of Interlukine-1Beta and Interlukine-2 in Chronic Periodontitis. Al- Mustansiriya J. 2012;23( 3).

[30]. Gorska R,Gergorek H, Kowalski J.Relationship between clinicalparameters and cytokine profiles in inflamed gingival tissue andserum samples from patients with chronic periodontitis. J Clin Periodontol. 2003; 30(12): 1946-52.

[31]. Zahraa F. Shaker and Batool H.Hashem. Study the role of proinflammatory and anti- inflammatory cytokines in Iraqi chronic periodontitis patients. J Bagh College Dentistry. 2012;24(1). 